\title{
ON-FARM MONITORING OF GROWTH PERFORMANCE OF INDIGENOUS GOAT IN AMHARA REGION OF ETHIOPIA
}

\author{
Kefyalew GOLLA ${ }^{1}$, Yeshambel MEKURIAW², Birhan KASSA ${ }^{3 \times 凶}$, Mussie HAILEMELEKOT² \\ 1South Gonder Zone Office of Agriculture, PO Box 550, Debre Tabor, Ethiopia \\ ${ }^{2}$ Bahir Dar University, College of Agriculture and Environmental Sciences, PO Box 550, Bahir Dar, Ethiopia \\ ${ }_{3}^{3}$ Andassa Livestock Research Center, P.O. Box 27, Bahir Dar, Ethiopia \\ ${ }^{\square}$ Email: birhankassa56@gmail.com; (1) ORCiD: 0000-0003-1949-8737 \\ Supporting Information
}

ABSTRACT: The study was conducted in Amhara region of Ethiopia, with the objective of characterizing the goat husbandry practice and on-farm monitoring of growth performance. The data were collected by interviewing 180 sample households who are selected purposively from three agro ecologies using semi- structured questioner. Besides, on farm monitoring of growth performance of 60 kids owned by farmers was done for three months. The data was analyzed using SPSS (version 20). Majority of households (68.9\%) have an experiences of feeding crop residue for their goat and faced feed shortage mainly during dry season (65.6\%). The main source of water for goat was river which is $51.1 \%$ in wet season and $88.9 \%$ in dry season. $51.7 \%$ of goat keepers had a separate goat house. The major disease reported were anthrax (40.6\%), goat pox (26.7\%) and foot and mouth disease (12.8). Purpose of goat keeping was mainly for income source $(62.8 \%) .84 .4 \%$ of the goat owners are experienced selection of male and female animal for production purpose. Body length and height (60.6\%) and color (34.4\%) were used as major selection criteria. Higher kidding was reported during months of October (20.55\%), November (39.44\%) and December (18.88\%). Drought (42\%), shortage of feed and water (38.5\%), disease and parasite (16\%), inconvenient climate condition (2\%) and lack of breeding male (1\%) were reported as major problems in the breeding objective. The overall birth weight, 60 days and 90 days weight of kids was $1.69 \pm 0.08 \mathrm{~kg}, 7.45 \pm 0.41 \mathrm{~kg}$ and $12.02 \pm 0.25 \mathrm{~kg}$, respectively. The survival rate of kids up to 90 days of age was $74 \%$. The production system of the area was characterized by mixed crop-livestock farming system on which crop residue was the main feed source of the goats as other livestock species. Even though the current productivity of goats in the area is fairly good, full potential need to be exploited by improving husbandry practices, applying appropriate disease prevention methods and applying strategic forage development and feeding practices.

Keywords: Birth weight, Husbandry practices, Indigenous goats, On-farm monitoring, Survival rate

\section{INTRODUCTION}

In Ethiopia; almost all goats are managed under extensive traditional systems and produce the lowest compared to other sub-Saharan African countries (Tesfahun et al., 2017). Ethiopian indigenous goats are genetically less productive as compared to temperate breeds (Mohammed et al., 2012; Abraham et al., 2018). Goats are important for diversified production, creating employment, increasing income, building capital, contributing to human nutrition and reducing risk, in efforts made so far to improve the productivity of indigenous goats is very little as compared to the concerns given to other livestock species such as cattle and sheep (Solomon et al., 2010). Despite the huge resource potential, production and export opportunities, goat production in Ethiopia is relatively undeveloped. There is considerable potential for goat production in the country, where goat milk and skin are valued commodities (ESGPIP, 2008; Mayberry et al., 2018).

Indigenous goats can inhabit a wide range of climates (Bangley, 2006) and have a huge socio-economic importance (FAO, 1999). For their small body size, goats have physical and bio-physical advantages over large ruminants. In recent years, it is increasingly becoming physically and bio-physically impossible to keep dairy and beef cattle in highly populated highlands of Ethiopia. Dairy goats, therefore, offer alternative to dairy cattle in such areas in Africa (Mohamed et al., 2002; Alemayehu and Kebede, 2017; Kahi and Wasike, 2019). The growing demand for meat from small ruminants, improving infrastructure (transport and information technology), and improvement in small ruminant husbandry techniques among producers provide opportunities to enhance the contribution of goats to smallholder farmers' livelihoods (Getahun, 2008). The current contribution of goats to the country's economy and producers livelihoods is however still below the total potential production capacity (Girma et al., 2000). Given the large population size with diverse breeds and their wide distribution across various agro-ecological zones and production systems, there is a huge potential to utilize goats to raise the socio-economic status of producers by improving goat productivity (Girma et al. 2000; Sheriff et al., 2020). Tach Gayint district is a place in which $23.7 \%$ of the district is "Kola" (lowland) and $63.2 \%$ is "Woyna Dega" / mid land/ which is suitable for small ruminant production especially for goats. However, goat production and productivity are challenged by shortage of feed, poor management system and disease (TGWADO, 2015). Even though the area has high number of goat population and potential for goat production, there is great problem in utilizing 
this resource potential optimally and more than $45 \%$ of the population living under poverty is supported by relief (TGWADO, 2015). This problem emanated from a number of factors such as low level of management skills, unavailability of inputs for goat production, needs and interests of individuals, poor agricultural practices and attitude. However, the above factors have not yet been extensively studied, therefore, there is a need to assess goat husbandry practices and productivity at farmer's level to fill the existing problems in the area. Therefore, it is better to systematically describe the productivity of goats in order to plan and design appropriate research and development interventions that are relevant for better improvement. Therefore, this study was conducted to fill the existing information gap with regard to husbandry practices and productivity of goat in Tach Gayint district. Therefore, the objective of this study was characterizing the smallholder goat husbandry practice and on-monitoring productivity of goat under the existing management condition.

\section{MATERIALS AND METHODS}

\section{Description of the study area}

The study was conducted at Tach Gayint district, Amhara region, Ethiopia. The district is located between $11^{\circ} 23^{\prime}-$ $11^{\circ} 44^{\prime}$ north latitudes, and $38^{\circ} 20^{\prime}-3^{\circ} 44^{\prime}$ east longitudes. It extends for about 40 kilometers in the north-south direction and about $44 \mathrm{~km}$ in the east-west direction and has a semi- compact shape and an area of $995 \mathrm{~km} 2$ and $82540.7 \mathrm{ha}$. The topography of the district consists of gorges and rugged terrain (54\%), mountains (23\%), and plain land (22\%), and it is divided into three agro- climatic zones: "Kola" (23.7\%) altitude $>500$, "Woyna Dega" (63\%) altitude>1500 and "Dega"(13.1\%) altitude $>\mathbf{2 3 0 0}$ More than 90 percent of its population lives in rural areas engaged predominantly on subsistence agricultural production. Agricultural production is mixed crop livestock and crop production is predominantly rain fed. Average annual rainfall is about $600-1000 \mathrm{~mm}$. The Mean annual maximum temperature ranges between $21-$ $23^{\circ} \mathrm{C}$ (TGDADO, 2015).

\section{Sampling Methods and Data Collection}

Sampling Techniques. The sampling method was multistage sampling technique. For the purpose of this study agroclimatic distribution of the district was used in order to stratify the Kebele in the district. Based on topography and agroclimate of the area, the district was divided into three strata as low land (23.7\%), midland (63.2 \%) and highland (13.1\%), (TGWADO, 2015). In the second stage, a proportional allocation technique was used in order to determine the number of sample Kebele from each stratum. In this manner, proportionally, two Kebele from the lowland, three Kebele from the midland and one Kebele from the highland i.e., a total of six Kebele were selected to undertake the study. Finally, households used for the study were selected using simple random selection method after identifying the goat owners from the community. Household that has at least 3 goats were selected for the survey. Accordingly, 30 households from each Kebele total of 180 households were randomly selected to participate in husbandry practices and productivity study of goats.

Data Sources. Both primary and secondary data were used on various aspects of goat husbandry practices. The primary data were collected from sample respondents through structured and semi structured questionnaire and through monitoring on growth of goats. The questionnaire covers various aspects of goat husbandry practice. Structured questionnaire was used to collect information on the following variables: purposes of keeping goats, feeds and feeding, breeding systems, housing, diseases and parasites and veterinary services. Secondary data were obtained from district Agricultural Development Office, Zonal Agricultural Department, NGOs and other published and unpublished sources. For data collection, development agents (DA's) working in the district were recruited, intensively trained and administered the questionnaire for 180 selected households in selected six Kebeles under the close supervision of the researcher.

\section{Focus group discussion}

In addition to informal survey collect qualitative data through focus group discussion before conducting the survey. Three focus group discussions were held at each agro-ecology with 9-12 key informants selected from the area, mainly the elders and those who have experienced goat keepers.

\section{Flock monitoring}

The study also includes monitoring of the, birth weight, pre -weaning growth rate and survival rate of kids. To make these monitoring 20 households from the three Kebeles of different agro ecologies (a total of sixty does) that have late pregnant goats were selected purposively from each three agro-ecologies by the researcher and development agents. The monitoring was done for three months. The birth weight of the kids was taken as soon as they are born using spring balance. The subsequent weight of kids was taken at 15 days interval and the analysis was made for birth weight, 60 days and 90 days weight. The live weight measurement was taken before feeding and watering and survival rate of kids was recorded starting from their birth.

\section{Data analysis}

The collected data was organized, summarized and analyzed using SPSS statistical package (SPSS version 20). A one-way analysis of variance was applied for quantitative dependent variable by a single factor (independent) variable 
such as livestock holdings, mortality rate, and flock dynamics. The difference between means was separated via Tukey HSD. In addition to this, General Linear Model (GLM) procedures were used to analysis the monitoring data. The following model was used:

$Y_{j k l}=\mu+S_{i}+B_{j}+P_{k}+A_{l}+e_{i j k l}$

Where:

$Y_{j k l}=$ Observation (birth weight, pre- weaning growth) ithsex thejth birth type born in the kth parity and the Ith agro ecology

$\mu=$ the overall mean common to all animals in the study

$S_{i}=$ fixed effects of the ith sex (1=male, $2=$ female)

$B_{j}=$ fixed effects of the $j$ th birth type (1= single, $2=$ multiple)

$P_{k}=$ fixed effects of the kth parity $(p=1,2,3$ and $>4)$

$A_{l}=$ fixed effect of the Ith agro-ecology (highland, midland and lowland)

$e_{j k l}=$ is the random error

\section{RESULTS and DISCUSSION}

\section{Husbandry practices}

Housing: Goats were mainly housed during rainy season; unlike other livestock species they were housed on fenced barn at the homestead. While, if the number was small they also commonly housed with sheep and other cattle inside a house. Respondents indicated that they had a separate goat house (51.7\%), and a house attached to the main a house $(36.7 \%)$, crash $(8.9 \%)$, and ground of the main house $(1.7 \%)$ and in the main house (1.1\%) to shelter their goat (table 8$)$. And majority of the respondents indicated that they separately housed fattening and young kids in the house. This might be due to giving of special care for them to fatten in short period of time and to follow the growth of kids, respectively. Majority of the respondents (85\%) responds that as they clean the house of goats daily. The remaining cleans the house/barn once a week, twice a week and three times a week. Majority of the respondents (97.2\% in wet season and $85 \%$ in dry season) indicated that they clean the barn daily (Table 2).

\section{Table 1 - Type of house used for goat production}

\begin{tabular}{lcc} 
Type of housing & Frequency & Percent \\
\hline In the main house & 2 & 1.1 \\
A house attached to the main house & 66 & 36.7 \\
A separately constructed sheep and goat house & 93 & 51.7 \\
Crash /barn/ & 16 & 8.9 \\
Ground of the main house & 3 & 1.7 \\
Total & 180 & 100.0 \\
\hline
\end{tabular}

\section{Table 2 - Hygienic practice of the barn in the study area}

\begin{tabular}{lc|c|c|c} 
& \multicolumn{2}{c|}{ Dry season } & \multicolumn{2}{c}{ Wet season } \\
\cline { 2 - 5 } Hygienic practice of the barn & Frequency & Percent & Frequency & Percent \\
\hline Daily & 153 & 85.0 & 175 & 97.2 \\
Once per week & 4 & 2.2 & 2 & 1.1 \\
Twice per week & 7 & 3.9 & 1 & 0.6 \\
Three times per week & 11 & 6.1 & 2 & 1.1 \\
Monthly & 2 & 1.2 & 1.7 & 180 \\
Not clean /only changing the barn & 3 & 100.0 & 2 \\
Total & 180 & & & 100 \\
\hline
\end{tabular}

\section{Feeds and Feeding}

From the total respondents $68.9 \%$ of them reported that they have experience of feeding crop residue for their goats, while $31.1 \%$ didn't have experience of feeding of crop residue for their goats. The main reason for low level of feeding of crop residue was unavailability (24.4\%) and not accepted by goats $(6.1 \%)$. The major crop residues reported were pea straw (37.2\%) and haricot bean straw (22.8\%). About $\mathbf{7 7 . 8 \%}$ of interviewed farmers indicated that they have experienced feed shortage for their goats. Shortage of feed was reported during dry season (65.6\%), rainy season (2.2\%) and throughout the year (11.1\%); and the others had enough feed throughout the year. As a main reason the feed shortage was due to shrinkage and declining in productivity of grazing land (34.4\%), cultivation, settlement and protection on 
grazing land (15\%), drought (17.8\%) and an increase in human population (6.7\%). The survey revealed that $77.2 \%$ of them let their animals to graze/browse with other flocks; while the others didn't let their goats to graze. $56.1 \%$ of the respondents indicated that they supplement their goats during dry season, wet season and throughout the year with respective percentage of $43.3 \%, 2.2 \%$ and $10.6 \%$. Farmers which were not supplementing because they didn't have accessibility of concentrate feeds and expensiveness of concentrate feeds.

Table 3- Major crop residues used for feeding of goats in Tach Gayint district

\begin{tabular}{lc} 
Major crop residues & Percent respondents \\
\hline Teff straw & 3.9 \\
Pea straw & 37.2 \\
Wheat straw & 2.8 \\
Haricot bean straw & 22.8 \\
Lentil straw & 0.6 \\
Vetch straw & 1.7 \\
Chick pea straw & 2.2 \\
\hline
\end{tabular}

\section{Table 4 - Seasonal Grazing/browsing system for goats in Tach Gayint district}

\begin{tabular}{lcc} 
Grazing system & Dry season (\%) & Wet season (\%) \\
\hline Free grazing & 46.2 & 18.9 \\
Partial grazing /tethered grazing & 39.4 & 22.2 \\
Zero grazing /tethered grazing & 14.4 & 58.9 \\
\hline
\end{tabular}

\section{Table 5 - Reasons for non-supplementing respondents in the study districts}

\begin{tabular}{lcc} 
Reasons for non-supplementation of concentrate feeds & Frequency & Percent \\
\hline Not accessible & 64 & 35.6 \\
Expensive & 11 & 6.1 \\
Not want to offer sheep and goats & 14 & 7.8 \\
\hline
\end{tabular}

\section{Water source and watering frequency:}

The respondents revealed that the major water sources for their goat were sourced from river $51.1 \%$ in rainy season and $\mathbf{8 8 . 9 \%}$ in dry season (Table 6). As the respondents revealed, during rainy season watering was once because many of the grass were fresh that holds water and during dry season watering frequency was twice and once a day (Table 7).

\section{Table 6 - Water source in dry and wet season for goats in Tach Gayint district}

\begin{tabular}{lcc} 
Source of water & Percent in wet season & Percent in dry season \\
\hline River & 51.1 & 88.9 \\
Pond & 1.1 & - \\
Rain water & 19.4 & - \\
Water harvest & 1.7 & - \\
Deep well & 5.6 & 2.2 \\
Pipe & 0.6 & - \\
Spring & 20.6 & 8.9 \\
\hline
\end{tabular}

Table 7- Watering frequency in dry and wet season for goats in Tach Gayint district

\begin{tabular}{lcccc} 
Watering frequency & \multicolumn{2}{c}{ Wet season } & \multicolumn{2}{c}{ Dry season } \\
\cline { 2 - 5 } & Frequency & Percent & Frequency & Percent \\
\hline Any time required & 92 & 51.1 & 16 & 8.9 \\
Once a day & 71 & 39.4 & 126 & 70.0 \\
Twice a day & 12 & 6.7 & 37 & 20.6 \\
Every three days & 5 & 2.8 & 1 & 0.6 \\
Total & 180 & 100.0 & 180 & 100.0 \\
\hline
\end{tabular}




\section{Goat diseases and vaccination strategy:}

The major diseases reported by the farmers were anthrax (40.6\%) goat pox (26.7\%) and foot and mouth disease (12.8) (Table 8). The reported diseases mainly occurred during long drought following floods and after small rainy season (Bett et al., 2017). Anthrax, foot and mouth diseases, Internal and External parasite were also reported on the same working area by Assefa et al. (2015) and PPR as a major goat disease was also reported by Wondwosen (2007). The reported diseases affect all age group of goat flock (73.3\%) following pregnant does and new born kids. Majority of the respondents $(96.7 \%)$ treat their sick animals by collecting medicaments from the public veterinarian clinic; the remaining respondents visit private clinics. About $\mathbf{8 6 . 1 \%}$ of the respondents indicated that they have an access for veterinary service within 1-10 $\mathrm{km}$ from their homestead. About $53.9 \%(n=97)$ respondents indicated that their goats received vaccine in recent times where as $46.1 \%(n=83)$ of respondents revealed that they didn't receive a vaccination. As indicated by $51.1 \%$ respondents, had face their goat death in this year and majority of death was reported during March which might be due to the short rainy season occurred in the area (Figure 1).

\section{Table 8 - Common goat disease and parasites in Tach Gayint district}

\begin{tabular}{lcc} 
Major disease & Number & Percent respondents \\
\hline Anthrax & 73 & 40.6 \\
Goat pox & 48 & 26.7 \\
Foot and mouth disease (FMD) & 23 & 12.8 \\
Nematodes /round worm/ & 10 & 5.6 \\
PPR & 2 & 1.1 \\
Total & 159 & 88.3 \\
\hline
\end{tabular}

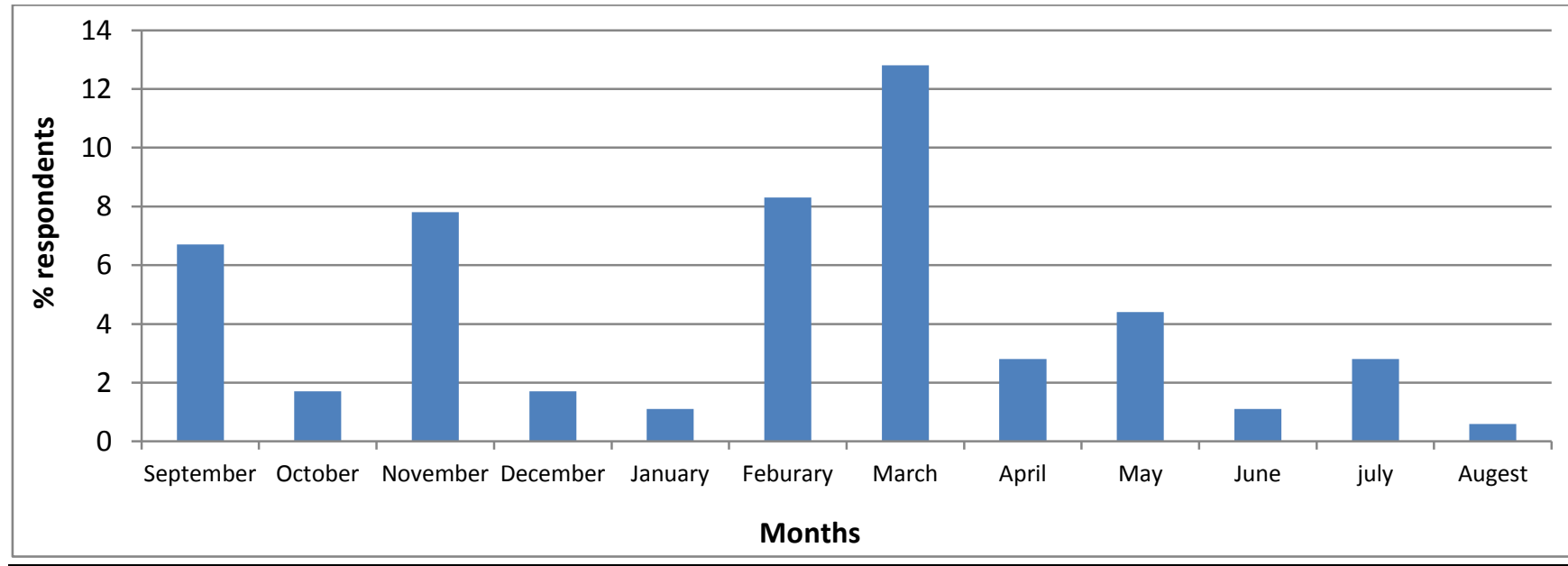

Figure 1 - Monthly Goat death reported in Tach Gayint district

\section{Breeding objective}

Purpose of keeping goats. Respondents indicated that they keep goat on their herd for many purposes from which income source through selling of the live goat is the major one (Table 9). From the focus group discussion result, it was observed that farmers also keep goats for different miscellaneous purposes viz. for dowry, social heritage and for other cultural values.

Selection criteria's and trait preference in goat production. From the total respondents, $84.4 \%$ of them experienced selection of male and female animal for production purpose. And $62.8 \%$ of respondents indicated that they had kept breeding male goat in their flock and the remaining $37.2 \%$ use neighboring goats and any buck in the field for mating of their doe. From the total farmers, 34.4\% of them reported that they experienced color as basic selection criteria on goat production system (Table 10). And the main selective color by the community was reddish white $(23.3 \%)$, red $(8.3 \%)$, white $(5.6 \%)$ and the combination of these all $(47.8 \%)$. In the goat production system, kidding occurred throughout the year with varying response (Figure 2). Higher kidding was reported during October, November and December months with respective percentage of $20.55 \%, 39.44 \%$ and $18.88 \%$. This might be due that in these months there is better grazing land, green grass and crop residues. In the breeding objective of the area, the major constraints those hinder productivity of goats were summarized in (Figure 3). Respondent's experiences culling of goats in their flock (45\%) and the remaining $52.8 \%$ hadn't experience culling of goats in their flock. As the respondents indicate the culling criteria's of goats in the flock were old age, sickness, reproductive problem, physical defect, unwanted color, and others with respective percentage of $16.1 \%, 19.4 \%, 2.8 \%, 5 \%, 2.8 \%$ and $3.3 \%$. 


\section{Table 9 - Purpose of keeping goats in the study district}

\begin{tabular}{lcc} 
Purposes & Frequency & Percent \\
\hline Sale/income source & 113 & 62.8 \\
Sale/income source and for meat & 58 & 32.2 \\
Sale/income source, for meat and manure & 9 & 5.0 \\
\hline Total & 180 & 100.0 \\
\hline
\end{tabular}

\section{Table 10 - Major selection criteria's of goat in the production system of the working district}

\begin{tabular}{lcc} 
Selection criterion & Frequency & Percent \\
\hline Color & 62 & 34.4 \\
Tail & 5 & 2.8 \\
Body length and height & 109 & 60.6 \\
Have no criteria & 4 & 2.3 \\
Total & 180 & 100.0 \\
\hline
\end{tabular}
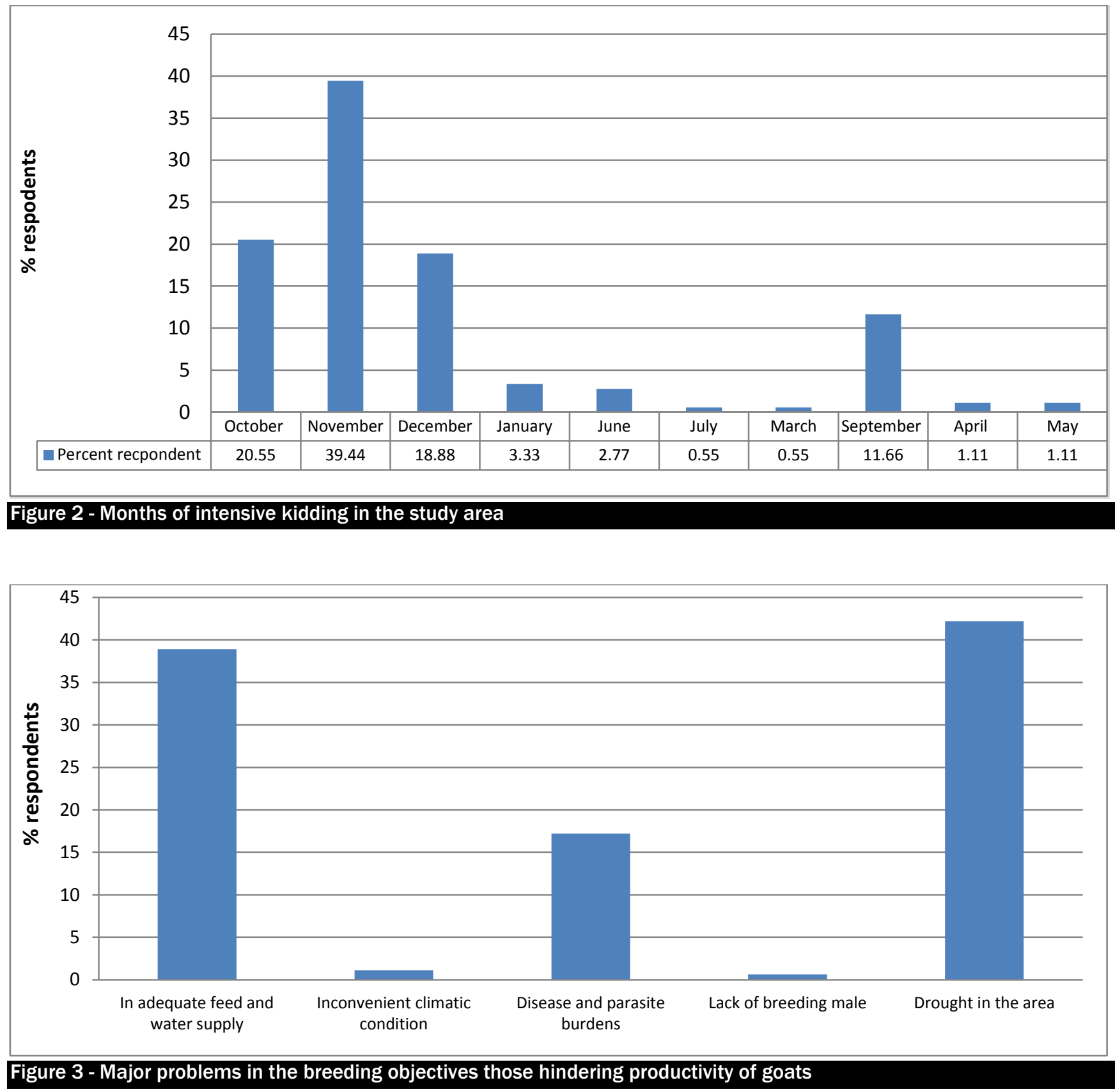
Growth performance, pre-weaning weight and survival rate of goats

The overall birth weight of kids was $1.69 \pm 0.08 \mathrm{~kg}$ and there was statistically significantly difference among agroecologies where higher birth weight was obtained from midland (Table 11). The overall 60 and 90 days weight of kids was $7.45 \pm 0.41 \mathrm{~kg}$ and $12.02 \pm 0.25 \mathrm{~kg}$ (Table 11). This result was higher than Agraw (2010) for highland goats and lower than the report of Zeleke (2007) for Somali goat kids and Tesfaye (2009) for goats at Metema district. Comparable results were reported by Belay and Mengistie (2013) for Abergelle kids. Similarly the weaning weight was also lower than Zeleke (2007) which was reported to be $11.67 \mathrm{~kg}$ for Somali goats and this difference might also be breed and production environment difference.

As indicated in the table above (Table 11), birth weight, 60 days and 90 days weight was influenced by the independent variables of agro-ecology, sex, parity and birth type. Similarly, significant effect of parity, sex and birth weight was also reported by Tesfaye (2009). Kids born at midland and lowland had better weight and also Survival rate. The 90 days weight was higher in the midland agro-ecologies than the others, which might be due to the presence of optional feed staffs from crop production. As a normal physiology, males had received higher birth weight, 60 days and 90 days weight. Kids born from parity 3 does had receive better birth, 60 and 90 days weight, this might be due to the act that does of these parity had better reproductive physiology both in uterine and mammary system.

Kids born at midland and lowland had better weight and also Survival rate. The $\mathbf{9 0}$ days weight was higher in the midland agro-ecologies than the others, which might be due to the presence of optional feed staffs from crop production. As a normal physiology, males had received higher birth weight, 60 days and 90 days weight. Kids born from parity 3 does had receive better birth, 60 and 90 days weight, this might be due to the act that does of these parity had better reproductive physiology both in uterine and mammary system. The survival rate of the current monitoring was $74 \%$. And the result was higher than Belay and Mengistie (2013) for Abergelle goats reported as $69 \%$ and $57 \%$ for the Borana kids and comparable with Arsi-Bale kids which was $75 \%$.

Table 11 - Birth weight, weaning weight and 90 days weight of goats in the study area

\begin{tabular}{|c|c|c|c|c|c|}
\hline Factors & $\mathbf{N}$ & Birth weight & $\mathbf{N}$ & 60 days weight & 90 days weight \\
\hline Over all & 60 & $1.69 \pm 0.08$ & 52 & $7.45 \pm 0.41$ & $12.02 \pm 0.25$ \\
\hline Agro ecology & & * & & NS & $\star \star \star *$ \\
\hline Highland & 20 & $1.56 \pm 0.17^{b}$ & 16 & $7.42 \pm 0.21$ & $9.60 \pm 0.228^{b}$ \\
\hline Mid land & 20 & $1.69 \pm 0.17^{a}$ & 19 & $7.54 \pm 0.04$ & $12.53 \pm 0.151^{a}$ \\
\hline Lowland & 20 & $1.65 \pm 0.13^{a b}$ & 17 & $7.51 \pm 0.07$ & $10.38 \pm 0.754^{a b}$ \\
\hline Parity & & $\star *$ & & * & $\star *$ \\
\hline 1 & 14 & $1.64 \pm 0.08^{b}$ & 12 & $7.63 \pm 0.32^{a}$ & $12.22 \pm .31^{b}$ \\
\hline 2 & 21 & $1.69 \pm 0.07^{\mathrm{ab}}$ & 16 & $7.18 \pm 0.07^{a}$ & $12.53 \pm .29^{a b}$ \\
\hline 3 & 9 & $1.79 \pm 0.21^{a}$ & 9 & $7.74 \pm 0.07^{a}$ & $13.03 \pm .34^{a}$ \\
\hline$>4$ & 16 & $1.72 \pm 0.11^{\mathrm{ab}}$ & 15 & $6.45 \pm 0.07^{b}$ & $13.03 \pm 0.34^{a}$ \\
\hline Sex & & * & & * & NS \\
\hline Male & 21 & $1.71 \pm 0.10$ & 20 & $7.16 \pm 0.28$ & $12.01 \pm 0.27$ \\
\hline Female & 39 & $1.62 \pm 0.11$ & 32 & $6.86 \pm 0.25$ & $11.03 \pm 0.28$ \\
\hline Birth type & & ** & & * & ** \\
\hline Single & 42 & $1.79 \pm 0.18$ & 39 & $7.75 \pm 0.40$ & $12.53 \pm 0.151$ \\
\hline Multiple & 18 & $1.59 \pm 0.08$ & 13 & $6.64 \pm 0.17$ & $10.38 \pm 0.754$ \\
\hline
\end{tabular}

\section{CONCLUSION}

Based on the husbandry practice adopted by the area, the production system of the survey district was characterized by mixed crop-livestock farming system on which crop residue was the main feed source of the goats as well as the other livestock species. The majority of the households do not possess private grazing land, which confirms that the goat production is mainly dependent on grazing/browsing and crop residues. Improvement of productive performance of goats need follow up and continuous evaluation of herd productive performance which allow to understand the major environmental factors to arrange continuous feeding and health monitoring in the flock. The monitoring data also indicated that, reproductive performance and birth weight of the kids was affected by agro-ecology and other factors; these facts assure improvement and designing the production system in the scientific way of goat production will improve the performance and income level of the farmer. As shown in the paper the goat production system is constrained by different problems those affect the breeding program and production potential, which shows the production system in the area is neglected and less attention was given for goat production. While other figures like the reproductive performance shows better result that indicate as the breed had better potential compared with other goat breeds of the country. 


\section{DECLARATIONS}

\section{Recommendations}

- As interlinked problems were reported by the result, more emphasis on improvement of the feeding practice, health monitoring and breeding program needs to be placed on the improvement of the productive and reproductive performance of goats.

- Characterization of the breed in the study area should better be conducted to well understand the potential of the breed and to set further conservation strategies.

\section{Conflict of interests}

The authors declare that they have no competing interests.

\section{Authors' contribution}

All authors contributed equally to this research work. All authors read and approved the final manuscript.

\section{REFERENCES}

Abraham H, Gizaw S, and Urge M. (2018). Identification of breeding objectives for Begait goat in western Tigray, North Ethiopia. Tropical Animal Health and Production, 50: 1887-1892. Google Scholar ; DOI: https://doi.org/10.1007/s11250-018-1640-5

Agraw A (2010). Phenotypic Characterization and Husbandry Practices of North-Western Highland Goats In West Gojjam Zone Of Amhara Region, Ethiopia. MSc thesis submitted to Bahir Dar University. Bahir Dar, Ethiopia.

Alemayehu K, and Kebede D (2017). Evaluation of Morphometric and Reproductive Traits of Indigenous Dairy Goat Types in North Western Amhara, Ethiopia. Iranian Journal of Applied Animal Science, 7(1), 45-51. Google Scholar ; Link

Assefa G, Hilemelekot M, Taye M, Wuletaw Z and Tesfa A (2015). A Survey on breeding practice, and productive performance of simada cattle in tach gayint district, Ethiopia. Journal of Life Science and Biomedicine, 5 (6): 171-180. Google Scholar ; Link

Belay D and Mengistie T (2013). Evaluation of Growth Performance of Abergele Goats under Traditional Management Systems in Sekota District, Ethiopia. Pakistan Journal of Biological Sciences, 16: 692-696. Google Scholar ; Link

Bett B, Kiunga P, Gachohi J, Sindato C, Mbotha D, Robinson T, Lindahl J, and Grace D (2017). Effects of climate change on the occurrence and distribution of livestock diseases. Preventive Veterinary Medicine, 137(Pt B):119-129. Google Scholar ; DOI: https://doi.org/10.1016/j.prevetmed.2016.11.019

ESGPIP (2008). "Ethiopia Sheep and Goat Productivity Improvement Program", Sheep and Goat Production Handbook for Ethiopia, Alemu Yami and R C Merkel (Eds.), pp. 5-26, Brana Printing Press, Addis Ababa, Ethiopia. Google Scholar

FAO (1999). Production Year Book: Food and Agricultural Organization (FAO). 52, Rome, Italy. Google Scholar

Getahun K (2008). Productive and Economic Performance of Small Ruminants in Town Production Systems of the Highlands of Ethiopia Doctoral Thesis, Hohenheim University, Cuvllier Verlag, Gottingen, Germany. Google Scholar

Girma A, Merkel R and Tilahun S (2000). Enhancing food security and income generation potential of families in southern Ethiopia through improved goat production and extension. In: Markel, R.C., Girma Abebe. And Goetsch, A.L (eds), The opportunities and challenges of enhancing goat production in East Africa: Proceeding of a conference held at Awassa, Debub University. pp. 113-117. Google Scholar

Kahi A, and Wasike C (2019). Dairy goat production in sub-Saharan Africa: current status, constraints and prospects for research and development. Asian-Australasian Journal of Animal Sciences, 32(8):1266-1274. Google Scholar ; DoI: https://doi.org/10.5713/ajas.19.0377

Mayberry D, Ash A, Prestwidge D, and Herrero M (2018). Closing yield gaps in smallholder goat production systems in Ethiopia and India Livestock Science, 214: 238-244. Google Scholar ; DOI: https://doi.org/10.1016/j.livsci.2018.06.015.

Mohamed M, Bezabih E, Jabbar M and Ehui S (2002). Analysis of Economic and Nutritional Impacts of Market-oriented dairy production in the Ethiopian highlands. Forth Coming,Socio-economic and Policy Working Paper International Livestock Research Institute ILRI Livestock Policy Analysis. Addis Ababa, Ethiopia. Google Scholar

Sheriff O, Alemayehu K and Haile A (2020). Production systems and breeding practices of Arab and Oromo goat keepers in northwestern Ethiopia: implications for community-based breeding programs. Tropical Animal Health and Production, 52(3): 1467-1478. Google Scholar ; DOI: https://doi.org/10.1007/s11250-019-02150-3.

Solomon A, Girma A and Kassahun A (2008). Sheep and Goat Production Systems in Ethiopia in: Alemu Yami and Merkel R.C. Sheep and Goat Production Handbook for Ethiopia, ESGPIP. Ethiopian Ministry of Agriculture and Rural Development, Ethiopia, 28-32. Link

Tesfahun B, Kebede K and Effa K (2017). Traditional goat husbandry practice under pastoral systems in South Omo zone, southern Ethiopia. Tropical Animal Health and Production, 49: 625-632. Google Scholar ; DOI: https://doi.org/10.1007/s11250-017-1240-9.

Tesfaye T (2009). Characterization of goat production systems and on- farm evaluation of the growth performance of grazing goats supplemented with different protein sources in Metema Woreda, Amhara Region, Ethiopia. MS Thesis. Haramaya University, Haramaya, Ethiopia. Google Scholar

Wondwosen K (2007). Husbandry practices of goats in Dalocha district, Southern Ethiopia. MSc. thesis submitted to Haramaya University. Google Scholar

Zeleke M (2007). Environmental influences on pre-weaning growth performance and mortality rates of extensively managed Somali goats in Eastern Ethiopia. Livestock Research for Rural Development, 19: Article \#186. Link 